\title{
COLORIMETRIC CHANGES OF WATERBASED FLEXOGRAPHIC INK PRINTED ON HEMP-BASED PAPERS EXPOSED TO ARTIFICIAL AGEING
}

\author{
Ivana Plazonić (iD), Irena Bates (iD), Vesna Džimbeg-Malčić (iD), Davor Zember \\ University of Zagreb, Faculty of Graphic Arts, Zagreb, Croatia
}

\begin{abstract}
The objective of the research was to investigate colorimetric changes of the waterbased flexographic ink printed on hemp-based papers subjected to artificial ageing. Three types of commercially available hemp office papers were used as printing substrate and by Esiproof instrument were printed manually in full tone with process waterbased flexographic inks. Both, papers and prints were exposed to artificial ageing in the Suntest XLS+ test chamber according ASTM D 6789-2 standard. The $L^{*}, a^{*}, b^{*}$ colour coordinates were measured and $\Delta E_{00}$ colour difference was calculated for different stages of light exposure in order to determine the change from the original color value. In total exposure time was $96 \mathrm{~h}$. The results have shown how the paper optical stability is dependent upon manufacturing process and that bleached hemp fibers provides better optical stability of papers than unbleached hemp fibers. Further, stability of prints made on hemp-based papers is for the most part defined by ink color, while the impact of the printing substrate is less pronounced. Generally, it was noticed how the most stable among prints were prints covered with the black ink, while prints with the yellow ink had the greatest changes in color under the influence of light.
\end{abstract}

Key words: artificial ageing, colorimetric changes, flexographic prints, hemp-based papers

\section{INTRODUCTION}

During past years, the worldwide capacity for production of non-wood plant fiber pulps has increased dramatically. These plants with widely differing characteristics, such as bagasse, wheat and rice straws, bamboo, hemp and kenaf are being used as a raw material in the manufacture of pulp and paper all over the world (Ashori, 2006; Krgović et al, 2004). Many of them are used still only on experimentally bases, while some of them are used in commercial paper mills. However, still the highest percentage up to $92 \%$ of world paper production is based on wood plant fibers (Fahmy et al, 2017). From the moment of production, the paper is subject to the natural ageing process which can be defined as a sum of all irreversible chemical and physical processes which occurs in organic materials slowly during time. It can be characterized as material with high sensitivity to temperature and light that are the most common degradation factors (Izdebska, 2016). Depending on its source (wood or different plants as cotton, flax, bamboo, wheat and hemp), each type of cellulose has particular characteristics that influence the properties and the stability of paper (Princi et al, 2008). But regardless of the origin of the cellulose fibers in paper structure, they contain to a greater or lesser extent cellulose, hemicellulose and lignin (Cocca et al, 2011). Generally, in lower-quality papers cellulose is embedded in a hemicellulose and lignin matrix. Pure cellulose during the natural process of paper ageing does not absorb visible light (over $400 \mathrm{~nm}$ ), but strongly absorb UV (under $200 \mathrm{~nm}$ ). Hemicellulose has similar behavior as cellulose, while lignin strongly absorbs in the UV and the visible region (Zervos, 2010). As paper is a multi-component material which can also include additives as starch, minerals, and synthetic polymers this component can also play a significant role in paper degradation due ageing (Area and Cheradame, 2011). After light absorption, the paper as printing substrate may generate chromospheres (as formaldehyde, furan, methoxy quinone and stilbene) in acid and alkaline hydrolysis and photo-oxidation degradation which results in paper discoloration (Xiaomeng and Guangxue, 2011). Printability of each substrate greatly depends on the interactions between the surface of printing substrate and used printing ink at the given printing process variables. The printing inks are a complex mixture of different components, which are classified by their function in ink matrix, and the composition of ink colorants is significantly dependent on the printing technology (Karlovits and Gregor-Svetac, 2011). Therefore, in addition to the paper change, the ink will also experience a change due to exposure to external factors as light, heat, humidity and air quality. All these natural processes of deterioration start as soon as ink is printed (Debeljak and Gregor-Svetac, 2010; Bates et al, 2012). So unquestionably the analysis of the colorimetric changes of prints must be perceived by two factors: the ageing of paper and ink. As the flexography is the fastest growing global analog print method which can be performed on a wide range of materials and substrates (absorbent and nonabsorbent) and with substantially improvement in quality due years (Izdebska, 2016), it is evident why 
the prints made by this printing technique are the subject of our research. Therefore, in this study, experiment was carried out in conditions of artificial aging where the ageing phenomenon of flexographic prints was analyzed through spectrophotometric changes of prints obtained on papers containing hemp fibers.

\section{METHODS}

\subsection{Printing substrates}

In this research three types of hemp-based office papers with approximately the same nominal grammage $\left(90 \mathrm{~g} / \mathrm{m}^{2}\right)$ were used as printing substrates (Table 1 ).

Table 1: Description of papers used as printing substrates

\begin{tabular}{|c|c|c|}
\hline \multicolumn{3}{|c|}{ Hemp-based office papers } \\
\hline Type 1 & Type 2 & Type 3 \\
\hline $\begin{array}{c}\text { unbleached, uncoated } \\
\text { handmade sustainable paper } \\
\text { made from } 100 \% \text { hemp plant } \\
\text { fiber }\end{array}$ & $\begin{array}{c}\text { non-chlorine bleached, uncoated } \\
\text { handmade sustainable paper } \\
\text { made from } 100 \% \text { hemp plant } \\
\text { fiber }\end{array}$ & $\begin{array}{c}\text { natural, unbleached white } \\
\text { industrial paper made from } 25 \% \\
\text { hemp and } 75 \% \text { post-consumer } \\
\text { waste fibers }\end{array}$ \\
\hline
\end{tabular}

\subsection{Full tone flexographic prints}

Hemp-based office papers were cut in dimensions $190 \mathrm{~mm} \times 40 \mathrm{~mm}$ and subjected to manual printing using a print tester Esiproof (RK print). The prints in cyan, magenta, yellow and black was made in full tone by Iroflex 917, waterbased flexographic inks manufactured by Sun Chemical. Prints were obtained using a ceramic anilox roller with $40 \mathrm{lin} / \mathrm{cm}, 60^{\circ}$ spread angle and a cell volume of $39.10 \mathrm{~cm}^{3} / \mathrm{m}^{2}$. The printing process was carried out at a temperature of $23^{\circ} \mathrm{C}$ and a relative humidity of $50 \%$.

\subsection{Artificial ageing}

Papers and prints were cut into strips $60 \mathrm{~mm} \times 90 \mathrm{~mm}$ and placed side by side in Suntest XLS+ test chamber, supplied with a daylight filter, which emit the UV radiation of wavelength in range of $290 \mathrm{~nm}-$ $800 \mathrm{~nm}$. The procedure of artificial ageing was carried out according to ASTM D 6789-02, during which the level of light intensity was $765 \pm 50 \mathrm{~W} / \mathrm{m}^{2}$, the temperature was kept at $22.6^{\circ} \mathrm{C}$ and relative humidity was $50 \%$. Exposure to the UV radiation was performed in two cycles for 48 hours. Approximately one hour of treatment under a xenon lamp corresponding to one day in nature (Debeljak and Gregor-Svetac, 2010; Izdebska et al, 2013).

The colorimetric values of papers as printing substrates and prints were determined using a spectrophotometer X-Rite SpectroEye. Color data were measured under illuminant D65, $2^{\circ}$ standard observers. On the basis of those measurements, the colorimetric difference $\left(\Delta \mathrm{E}_{00}{ }^{*}\right)$, which appeared after ageing, were calculated with the following equation (Luo et al, 2001), using the corresponding unaged paper or print as reference:

$$
\Delta E_{00}=\sqrt{\left(\frac{\Delta L^{I}}{k_{L} S_{L}}\right)^{2}+\left(\frac{\Delta C^{I}}{k_{C} S_{C}}\right)^{2}+\left(\frac{\Delta H^{I}}{k_{H} S_{H}}\right)^{2}+R_{T}\left(\frac{\Delta C^{J}}{k_{C} S_{C}}\right)\left(\frac{\Delta H^{I}}{k_{H} S_{H}}\right)}
$$

The results reported are the average of ten measurements from each sample.

\section{RESULTS AND DISCUSSION}

The analyzed papers and flexographic prints behaved differently during artificial ageing.

\subsection{Colorimetric changes of hemp-based office paper as printing substrate}

In the first stage of the study, the optical properties of papers used as printing substrates were analyzed and the changes in the color $\left(\Delta \mathrm{E}_{00^{*}}\right)$ in relation to the artificial aging time are shown in Figure 1. 


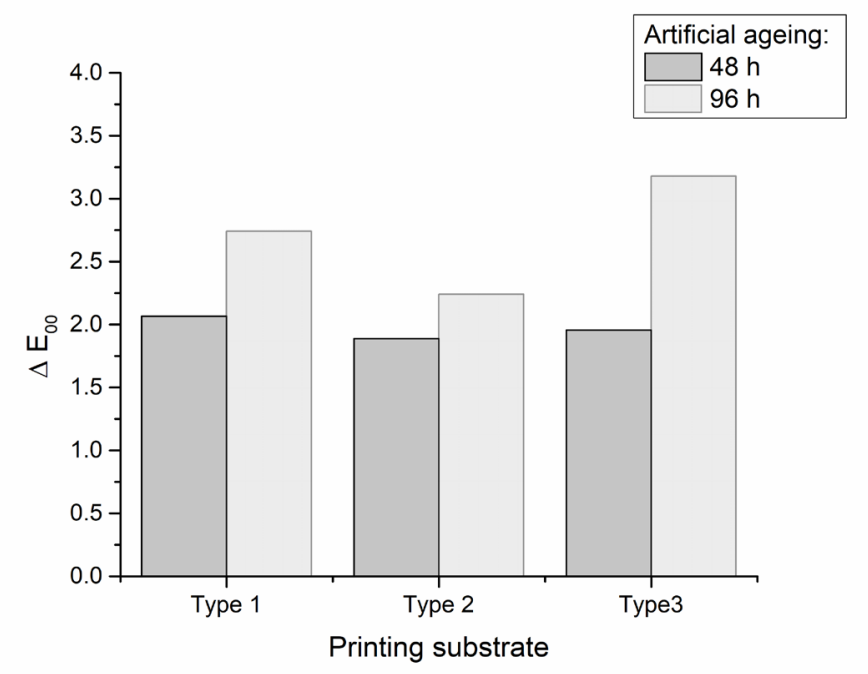

Figure 1: Color difference of tree types of paper used as printing substrate during artificial ageing

The influence of UV radiation treatment on initial color of all printing substrates types was more pronounced with longer ageing treatment period. It was noticed that the most stabile paper type is Type 2 (made from bleached virgin hemp fibers), while the color change during ageing treatment of 96 hours is the most progressive at the paper Type 3 (made form admixture of hemp fibers and post-consumer waste fibers). In previous researches it is proven how process of bleaching fibers used for paper production is significant stage in paper production which ensures optical stability of paper during different ageing treatments (Plazonić et al, 2018; Plazonić et al, 2020).

\subsection{Colorimetric changes of prints}

The calculated differences in color $\left(\Delta \mathrm{E}_{00}{ }^{*}\right)$ of prints on all three types of paper after 48 and 96 hours of ageing treatment are presented in Figures $2 \mathrm{a}-2 \mathrm{~d}$. It was noticed that light effect on prints strongly depends on the particular ink type. Cyan, magenta, yellow and black inks have not the same stability on light. Generally, it was noticed how the most stable among prints was the black ink, while the yellow ink under the influence of light had the greatest changes in color. From the $\Delta E_{00} *$ results calculated for prints it was observed how the ink plays a greater role in the stability of the print than the printing substrate. Generally all prints, regardless of the type of ink and printing substrates, after first 48 hours of ageing treatment show very small noticeable difference for standard observer $\left(\Delta \mathrm{E}_{00} * \leq 2\right)$, while further exposure to UV radiation treatment have the strongest impact on yellow ink prints $\left(\Delta \mathrm{E}_{00} *>2\right)$.

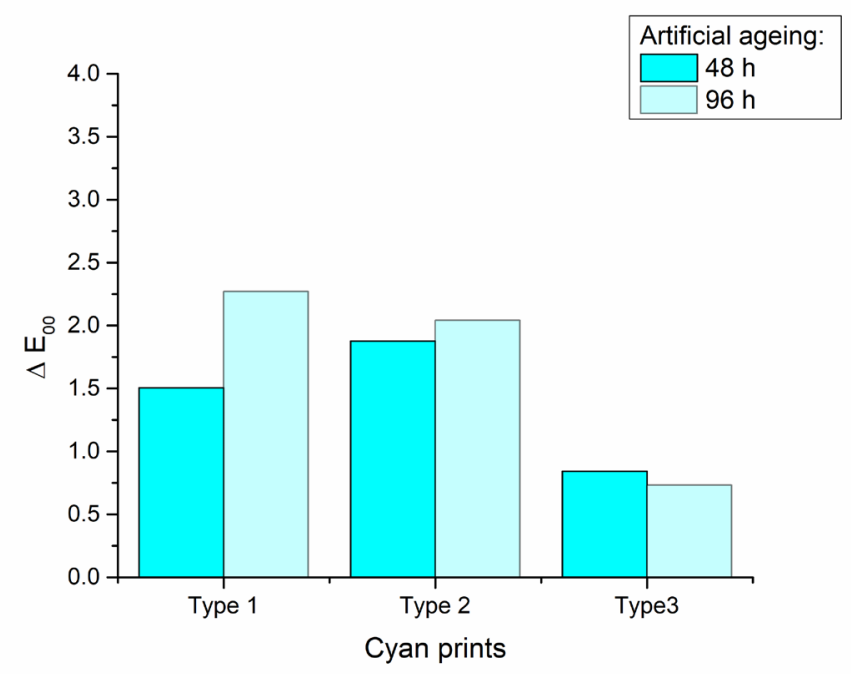

Figure 2a: Color difference of cyan prints on papers during artificial ageing 
From the results shown in Figure $2 \mathrm{a}$ it is evident how the smallest color difference occurs on cyan prints made on paper Type 3 which have shown the smallest stability on light above all analyzed printing substrates. Cyan prints on paper Type 3 have a negligee color difference to observer after 48h and $96 \mathrm{~h}$ of ageing treatment $\left(\Delta \mathrm{E}_{00} *\right.$ after $48 \mathrm{~h}$ and after $96 \mathrm{~h}$ is $\left.<1.0\right)$. On the other hand, cyan prints on printing substrates made only from hemp fibers show similar stability to the influence of UV radiation as the substrate on which they are printed.

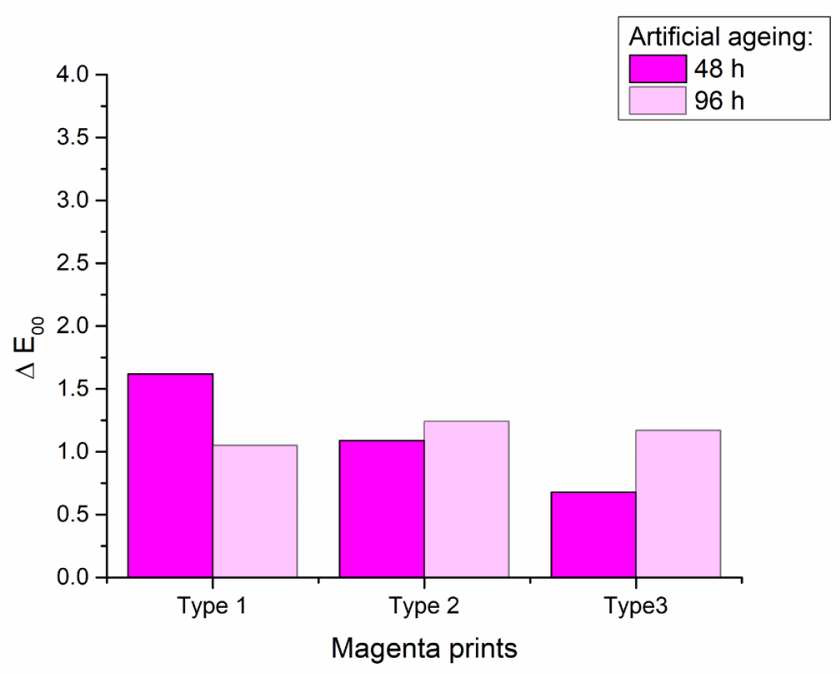

Figure 2b: Color difference of magenta prints on papers during artificial ageing

From Figure $2 \mathrm{~b}$ it is visible how magenta prints have similar stability on UV radiation treatment regardless on which printing substrate is printed. It is noticed how in the first 48 hours of treatment all the changes in magenta color occurs and with further treatment not significant changes in color were noticed.

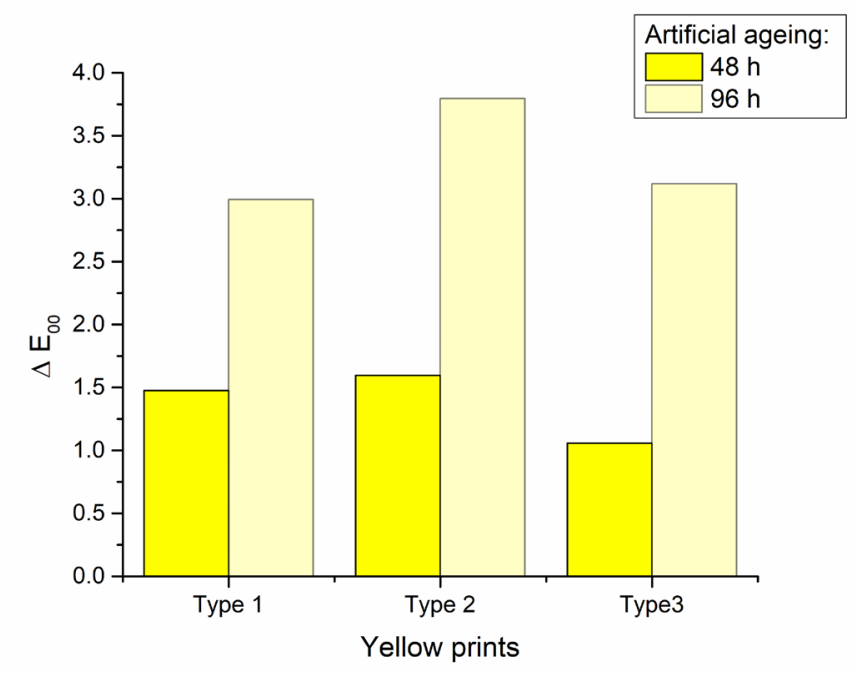

Figure 2c: Color difference of yellow prints on papers during artificial ageing

As shown in Figure 2c with increasing treatment time the color difference of yellow prints increases exponential at all three analyzed printing substrates. After first 48 hours of ageing treatment the change in yellow color for all prints was in range from 1.1 to 1.6, while with the additional 48 hours of ageing treatment these changes were become noticeable ( $\Delta \mathrm{E}_{00} *$ is in range from 3.0 to 3.8). The highest color difference was observed on the paper Type 2 especially more significant after $96 \mathrm{~h}$ of ageing treatment. 


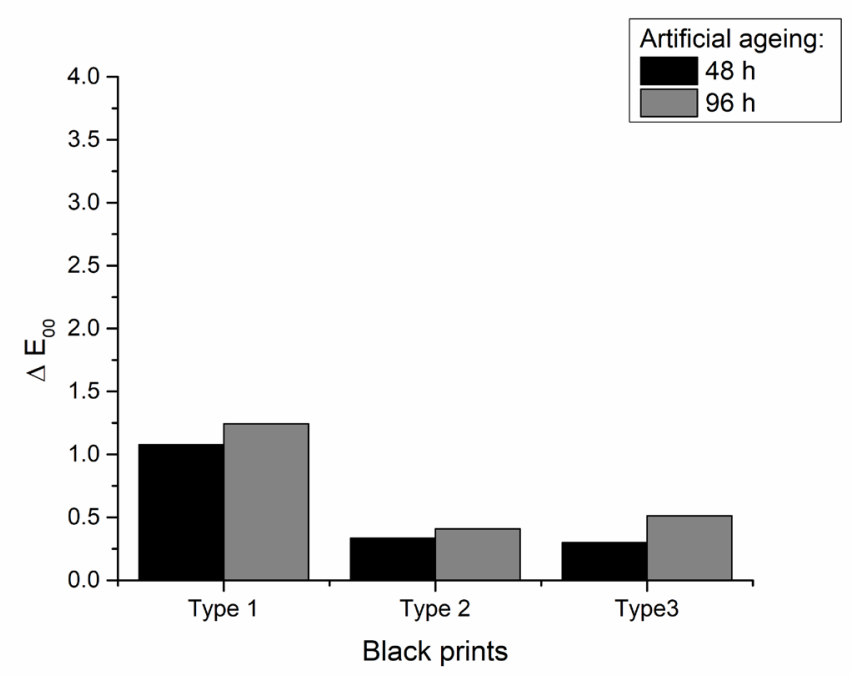

Figure 2d: Color difference of black prints on papers during artificial ageing

From the Figure $2 d$ it is clearly visible that the color differences of black prints at all analyzed printing substrates are exceptionally low $\left(\Delta \mathrm{E}_{00} * \leq 1.0\right)$. Exceedingly small color changes of black ink prints occur within the first 48 hours of aging, while with additional $48 \mathrm{~h}$ of ageing the changes in color are negligible. However, among all observed prints the most stable black print is the one made on printing substrate Type 2, while the print with the highest change in color is the one made on Type 1 (unbleached 100\% hemp based paper).

\section{CONCLUSIONS}

The aim of this study was to investigate colorimetric changes of printed office hemp-based papers subjected to artificial ageing. The results have shown that the lowest impact of UV radiation treatment was on paper made only from bleached hemp fibers. However, this office paper as printing substrate has not provided the best stability of prints under UV radiation treatment for all flexographic inks. From all results it could be concluded how color stability of prints are mainly defined by the type of pigment and ink, but also by the ink interaction with the printing substrate. Once again it was proven how the most stable are prints with the black ink, while prints with the yellow ink under the influence of light had the greatest changes in color.

\section{ACKNOWLEDGMENTS}

This work has been supported by the University of Zagreb.

\section{REFERENCES}

[1] Area, M.-C., Cheradame, H.: "Paper aging and degradation: recent findings and research methods", BioResources 6 (4), 5307-5337, 2011.

[2] Ashori, A.: "Nonwood Fibers- A Potential Source of Raw Material in Papermaking", Polymer-Plastics Technology and Engineering 45 (10), 1133-1136, 2006. doi:10.1080/03602550600728976.

[3] Bates, I., Džimbeg-Malčić, V., Itrić, K.: "Optical deterioration of samples printed with basic Pantone inks", Acta Graphica 23 (3-4), 79-90, 2012.

[4] Cocca, M., D'Arienzo, L., D'Orazio, L.: "Effects of Different Artificial Agings on Structure and Properties of Whatman Paper Samples", International Scholarly Research Notices 2011 (7), 2011. doi:10.5402/2011/863083.

[5] Debeljak, M., Gregor-Svetec, D.: "Optical and Color Stability of Aged Specialty Papers and Ultraviolet Cured Ink Jet Prints", Journal of Imaging Science and Technology ${ }^{\circledR} 54$ (6), 060402-1060402-9, 2010. doi: 10.2352/J.ImagingSci.Technol.2010.54.6.060402. 
[6] Fahmy, Y., Fahmy, T. Y. A., Mobarak, F., El-Sakhawy, M., Fadl, M.H.: “Agricultural Residues (Wastes) for Manufacture of Paper, Board, and Miscellaneous Products: Background Overview and Future Prospects", International Journal of ChemTech Research 10 (2), 424-448, 2017. doi:10.5281/zenodo.546735.

[7] Izdebska, J., Żołek-Tryznowska, U., Książek, T.: "Influence of artificial aging on cellulose film. The optical properties of printed and non-printed biodegradable film bases", Agro FOOD Industry Hi Tech, 24 (5), 52-56, 2013.

[8] Izdebska, J.: "Aging and Degradation of Printed Materials", In book: "Printing on Polymers: Fundamentals and Applications, Chapter: 22", (Elsevier, Chadds Ford, USA, 2016), page 353-370. doi:10.1016/B978-0-323-37468-2.00022-1.

[9] Izdebska, J.: "Flexographic Printing", In book: "Printing on Polymers: Fundamentals and Applications, Chapter: 11", (Elsevier, Chadds Ford, USA, 2016), page 179-197. doi:10.1016/B978-0-323-374682.00022-1.

[10] Karlovits, M., Gregor-Svetec D.: “Comparison Of Durability Between Uv Inkjet And Conventional Offset Prints Exposed To Accelerated Ageing", Journal of Graphic Engineering and Design 2 (2), 10 15, 2011.

[11] Krgović, M., Mijatović, B., Nikolić, S., Nadežda, B.: “Hemp as a raw material for fiber and paper production", Hemijska industrija 58 (5), 213-216, 2004. doi:10.2298/HEMIND0405213K.

[12] Luo, M. R., Cui, G., Rigg, B.: "The development of the CIE 2000 colour-difference formula: CIEDE2000", Color Research \& Application 26 (5), 340 - 350, 2001. doi: 10.1002/col.1049.

[13] Plazonić, I., Malnar, L., Džimbeg-Malčić, V., Barbarić-Mikočević, Ž., Bates, I.: “Changes in the optical properties of hemp office papers due to accelerated ageing", Proceedings of 9th international symposium on graphic engineering and design 2018, (Grafički centar GRID:, Novi Sad, 2018), pages 121-127.

[14] Plazonić, I., Džimbeg-Malčić, V., Bates, I., Barbarić-Mikočević, Ž.: "Effects of Photo-oxidation on the Properties of Hemp Office Papers", International Journal of Technology 11(2), 215-224, 2020. doi: 10.14716/ijtech.v11i2.3196.

[15] Princi, E., Vicini, S., Marsano, E., Trefiletti, V..: "Influence of the artificial weathering on thermal stability of paper-based materials", Thermochimica Acta 468, 27-34, 2008. doi:10.1016/j.tca.2007.11.019.

[16] Xiaomeng, C., Guangxue C.: "Study on Photoaging Phenomenon of Digital Inkjet Presswork", Advanced Materials Research 174, 219-222, 2011. doi:10.4028/www.scientific.net/AMR.174.219.

[17] Zervos, S.: "Natural and Accelerated Ageing of Cellulose and Paper: A Literature Review", In book: "Cellulose: Structure and Properties, Derivatives and Industrial Uses, Chapter: 5", (Nova Science Publishers, Inc.,UK, 2010).

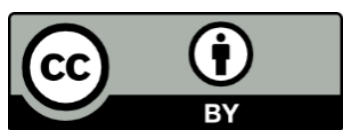

(C) 2020 Authors. Published by the University of Novi Sad, Faculty of Technical Sciences, Department of Graphic Engineering and Design. This article is an open access article distributed under the terms and conditions of the Creative Commons Attribution license 3.0 Serbia (http://creativecommons.org/licenses/by/3.0/rs/). 